\title{
REFLECTION
}

\section{Why Physician Guidance Matters: A Night of Neuralgia, Meningitis, and WebMD}

\author{
Anson Au, MSc, FRAS \\ University of Toronto, Toronto, Canada
}

Conflicts of interest: author reports none.

\author{
CORRESPONDING AUTHOR \\ Anson Au, MSc, FRAS \\ 725 Spadina Avenue \\ Department of Sociology, University of \\ Toronto \\ Toronto, ON M5S 2J4 \\ Canada \\ anson.au@mail.utoronto.ca
}

\begin{abstract}
During a night of severe pain and weakness, I found several plausible-sounding diagnoses online: occipital neuralgia, nerve damage, and meningitis. The next day, I consulted a physician who did not offer professional guidance; instead the physician suggested tests entirely based on my self-diagnoses. What resulted was an unnecessary array of lengthy and costly testing that did not diagnose the problem. Although my symptoms disappeared on their own, I was left feeling mistrustful of my physician and ultimately stressed and anxious. Against the backdrop of my experience, I highlight the potential harms of Internet-based self-diagnoses and the importance of collaboration and trust in the patientphysician relationship.
\end{abstract}

Ann Fam Med 2019;17:462-464. https://doi.org/10.1370/afm.2414.

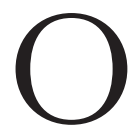
$\mathrm{n}$ a bland Thursday night, I felt a thorn throb in my head. Believing the headache would pass with the night, I went to sleep around midnight. A troubled history with insomnia had primed me for what was usually a long wait for sleep, especially on a night with a kind of pain I hadn't felt in a while. As the night dragged on, the pain sharpened like a knife piercing into the back of my head. By 2:00 AM, I was close to tears. In the dead of the night, with nothing but my pain, I spent my time between shooting frequent glances at the clock in silent prayer that all this would pass and perusals of WebMD, among a myriad of medical websites, on possible diagnoses. "A sharp jabbing pain in the neck, back of the head, and behind the eye," one page convincingly read, "are possible symptoms of occipital neuralgia." Occipital neuralgia. That was what I had.

By 3:00 AM, the thorn had sprung vines and blossomed into a network. The pain began to spread down my spine to my lower back. Like with my head, what started as a mild throb sweltered into a jagged pain around the tailbone of my spine. "Pain in multiple places is potentially a sign of nerve damage," another page read. I then recalled how a 68 -year-old relative of mine had a genetic condition where the cylindrical bones in his lumbar vertebrae were smaller in diameter, pressing the nerves within to cause pain in different parts of the body. Nerve damage due to this genetic condition I had to have. With a double meaning, "this was it," I thought.

I frantically kept calling my insurance company-and kept hearing that the line could not connect. I was in Seoul, South Korea at the time for a research fieldwork trip, away from my home country, and required authorization before any health care service to be covered.

By 5:00 AM, the pain shot through my legs and my hands tingled from numbness. I could no longer walk without collapsing from crippling weakness and pain. I lay in bed, drowning in fear of what the pain meant. The only feeling left that wasn't burdened with pain remained in my fingers-it was just enough for me to keep using my phone, like a spark of hope or a cruel joke. With everyone I knew asleep or thousands of miles away, I scrolled furiously through the medical wisdom of the Internet. 
"Drowsiness, stiff neck, severe headaches, poor motor control are possible symptoms of meningitis. Other symptoms could include confusion, rashes, aversion to light..." Seeing confusion in the list, my mind raced: was I confused as well? What would confusion feel like? Why is this all happening? Perhaps I was confused too. It definitely had to be meningitis now.

As the darkness painted on my window loosened into lighter shades of day, very slowly, around 9:00 AM, my unnamed affliction, like a sadist now bored with its conquest, began to retreat. I took the chance to call my insurance company again and successfully obtained approval. Before rejoicing in some relief from the pain, and able to walk again, I bolted to the closest hospital — a national university hospital—where I was directed to an international clinic inside.

There, I met Dr Kim.

"What seems to be the problem?" he asked.

"I believe I have meningitis." I stated, matter-of-factly.

"Really? Why?"

I went on to describe one of the worst nights of my life.

"Well, let's see then." He went on to prescribe a blood test, which eventually ruled out meningitis and stated I should be fine.

But I wasn't convinced. Days later, a conversation with a friend reminded me of the raw squid salad dish I had had the night of my ordeal. WebMD came back with new diagnoses: food poisoning or parasites. As if the two were a choice, I became fixed on the worse prognosis. With renewed determination, I returned to Dr Kim and told him the ordeal I experienced that night was a result of parasites.

"Ah, I'll send you for two tests for parasites then." He entered the order into his computer, then swiveled over to face me. "So, do you have any more theories about your condition?"

Both parasite tests also came back negative. After a full week and a half, my pain and other symptoms dissipated on their own, which Dr Kim was pleased about, but still said he had no idea of the cause, yet asserted there was no need to worry about the matter, now that it had passed. If I was not in physical distress, then I simply need not worry, I was told.

While I rejoiced in the knowledge that I was apparently fine, I wondered: could the stress I experienced and the lengthy, costly procedures that I undertook have been avoided if Dr Kim had not entertained all of my opinions? Did he mistake giving the patient control for patient-centered care?

A chief merit of patient-centered care is its collaborative nature that facilitates physician-patient communication by allowing patients like me to speak openly and contribute to the interaction. ${ }^{1}$ It is by giving patients information and explaining medical options tempered with a professionally trained opinion that they are empowered. ${ }^{2}$ The dangers this model was meant to circumvent are well understood: an overbearing physician dominating the discussion, disregard of the patient's opinion, patient mistrust in the physician, and ultimately misdiagnoses or a prescribed solution that the patient disagrees with and refuses to adhere to. ${ }^{3}$ But my encounter with Dr Kim lays bare the dangers of the reverse; how there's a tipping point in this partnership, where giving only the patient the power to speak has the same consequences as only giving voice to the physician-a misdiagnosis that fails to address the patient's needs.

A constellation of diagnoses swirled around my head, and Dr Kim prescribed a lengthy, costly test to treat each one-and invited me to disclose any further ideas for him to keep testing. This signaled to me that I was right to worry; that I had reason to develop more concerns, with no end in sight. Dr Kim not only exacerbated each concern I had, but also my overreactive tendency to develop concerns by giving legitimacy to my conclusions without assessing the evidence substantiating them.

An ongoing relationship and collaborative dialogue were missing. Patients need control and input into the final decision, but with proactive guidance through testing and treatment options from physicians who know them; they need the agency to draw their own lines, but with a steadying hand laid over their own, particularly on the Internet when the veracity of information is made tenuous by its sheer volume and lack of quality control and as people increasingly turn to and trust online websites as credible sources of knowledge. ${ }^{4-6}$

My experience shows the need for a sense of trust woven into the fabric of a collaboration whose importance goes beyond the testing phase to effect better physician-patient communication and health outcomes. $^{7.9}$ In this case, it would have afforded me a sense of security. Without it, even after the dust had settled after my ordeal, I could not divorce myself from the nervous tic that kept me self-diagnosing in the first place, despite the fact that no symptom had resurfaced after my week-long ordeal. Was I really all right? Or was something rusting inside me, waiting to break? Had something already been broken?

The entire process was transformative. Where before I believed I only had the responsibility to find a physician ${ }^{8}$ and my physician the responsibility to heal me, ${ }^{9}$ I realize now that we both needed to enforce another two-way responsibility. I needed to be heard 
and guided and he needed to listen and inform, neither overturning or blindly accepting the other-so that I might not capsize into illusory waves of neuralgia, meningitis, and other diseases thrashing about in a sea of WebMD.

To read or post commentaries in response to this article, see it online at http://www.AnnFamMed.org/content/17/5/462.

Key words: clinical decision making; diagnosis; physicians; patients; trust

Submitted August 10, 2018; submitted, revised, March 14, 2019; accepted April 9, 2019.

\section{References}

1. Epstein RM, Street RL Jr. The values and value of patient-centered care. Ann Fam Med. 2011;9(2):100-103.

2. Stewart M, Brown JB, Donner A, et al. The impact of patientcentered care on outcomes. J Fam Pract. 2000;49(9):796-804.
3. Epstein RM, Franks P, Fiscella K, et al. Measuring patient-centered communication in patient-physician consultations: theoretical and practical issues. Soc Sci Med. 2005;61(7):1516-1528.

4. Au A, Chew M. How do you feel? Managing emotional reaction, conveyance, and detachment on Facebook and Instagram. Bull Sci Technol Soc. 2017;37(3):127-137.

5. LaRose R, Lin CA, Eastin MS. Unregulated Internet usage: addiction, habit, or deficient self-regulation? Media Psychol. 2003;5(3): 225-253.

6. Ryan A, Wilson S. Internet healthcare: do self-diagnosis sites do more harm than good? Expert Opin Drug Saf. 2008;7(3):227-229.

7. Street RL Jr, Makoul G, Arora NK, Epstein RM. How does communication heal? Pathways linking clinician-patient communication to health outcomes. Patient Educ Couns. 2009;74(3):295-301.

8. Au A. Finding a doctor to trust: the journey of a sexual minority patient. Fam Med. 2018;50(7):546-547.

9. Au A. Online physicians, offline patients: professional identity and ethics in social media use. Int J Sociol Soc Policy. 2018;38(5/6): 474-483.

\section{CHANGE-OF-ADDRESS FORM \\ FAMNILY MEDICINE}

Please complete this form and mail to the following address or fax to Annals Circulation at 913-906-6080:

Annals of Family Medicine, Circulation Department, 11400 Tomahawk Creek Pkwy, Leawood, KS 66211-2680

Check if member of sponsoring organization:

$$
\begin{array}{ll}
\square \text { AAFP } \square \text { ABFM } \square \text { STFM } \square \text { ADFM } \\
\square \text { AFMRD } \square \text { NAPCRG } \square \text { CFPC }
\end{array}
$$

ID number from label on your journal cover

OLD Information (Please print.)

\begin{tabular}{ll}
\hline Name \\
\hline Company (if applicable) \\
\hline Address (Street plus Apt or Ste) \\
\hline City & Postal Code (9-digit ZIP for US) \\
\hline Country & Fax \\
\hline Telephone & \\
\hline E-Mail &
\end{tabular}

NEW Information (Please print.)

\begin{tabular}{lc}
\hline Name \\
\hline Company (if applicable) \\
\hline Address (Street plus Apt or Ste) \\
\hline City & \\
\hline Country & Postal Code (9-digit ZIP for US) \\
\hline Telephone & Fax \\
\hline E-Mail &
\end{tabular}

